\title{
POLA SPEKTRAL TANAMAN TEBU (SACCHARUM OFFICINARUM L.) MENGGUNAKAN SPEKTROFOTOMETER DAN CITRA PENGINDERAAN JAUH DI KABUPATEN BANTUL
}

\author{
Karen Slamet Hardjo ${ }^{1}$, Like Indrawati ${ }^{2}$ \\ ${ }^{1,2}$ Program Studi Penginderaan Jauh dan SIG, Departemen Teknologi Kebumian, \\ Sekolah Vokasi Universitas Gadjah Mada \\ ${ }^{1}$ karen@geo.ugm.ac.id \\ ${ }^{2}$ like.indrawati@ugm.ac.id
}

\begin{abstract}
Sugar becomes one of the commodities targeted to achieve Indonesia national food security. Sugar is produced from sugarcane (Saccharum officinarum L.), extensive plantations require effective and efficient handling and low cost. Remote sensing is a technology that is considered appropriate to answer those needs, through remote sensing image can be analyzed to the physical condition of sugar cane plant based on the spectral response recorded on the image. The spectral response captured by the sensor is expected to help analyze this plant in relation to plant growth, plant health, as well as the production of sugar yields in sugarcane. The lack of spectral pattern research, especially the in situ spectral pattern that is used as a reference for remote sensing data analysis, makes this research important to do. Bantul Regency is a region that has a large agricultural area, including sugar cane plantation.

The method used in this research is digital data processing on remote sensing image to be analyzed spectral pattern especially in sugarcane which then compared with data of spectral pattern of sugar cane which is measured directly in the field using spectrophotometer. Spectral patterns obtained from two sources are then analyzed to determine the agility of sugarcane.

The result of this research is give description about spectral pattern characteristic or reflectance pattern in sugar cane plant so it can be used for mapping of sugar cane plantation. The Sugar cane Plant reflected curve from the field measurements by spectrophotometer is noticeably smoother and has more wavelengths than the reflected curves of the Landsat 8 OLI Image. The distribution of sugar cane plant based on the spectral reflectance pattern of the object of field measurement is more relevant than the distribution of sugarcane based on the spectral reflection pattern of the object from Landsat 8 OLI Image. The classification of the field measurement spectral library and the Landsat 8 OLI Image shows that the spectral library of field measurements is better to serve as the basis for spectral-based mapping than the sampled spectral libraries in Landsat 8 OLI Image.
\end{abstract}

Keywords : remote sensing, Landsat 8, spectral pattern, spectrophotometer, sugar cane

\section{PENDAHULUAN}

Gula adalah suatu karbohidrat sederhana yang menjadi sumber energi dan komoditi perdagangan utama. Gula paling banyak diperdagangkan dalam bentuk kristal sukrosa padat. Gula sebagai sukrosa diperoleh dari nira tebu, bit gula, atau aren. Negara-negara penghasil gula terbesar adalah negara-negara dengan iklim hangat seperti Australia, Brasil, dan Thailand. Hindia-Belanda (sekarang Indonesia) pernah menjadi produsen gula utama dunia pada tahun 1930-an, namun kemudian tersaingi oleh industri gula baru yang lebih efisien. Namun, saat ini di Indonesia gula menjadi salah satu komoditas yang ditargetkan dapat mencapai ketahanan pangan nasional (Anonim, 2012). 
Ketahanan pangan adalah ketersediaan pangan dan kemampuan seseorang untuk mengaksesnya (Anonim,2011). Ketahanan pangan gula hanya bisa dicapai jika telah tercapai swasembada gula. Saat ini pemerintah telah menetapkan kebijakan pembangunan perkebunan demi mewujudkan swasembada gula nasional. Kebutuhan gula nasional sampai 2019 diproyeksikan sebesar 6,61 juta ton.

Guna mendukung suksesnya swasembada gula nasional, maka pengelolaan kebun yang baik, efektif dan efisien, sangat diperlukan, mulai dari perencanaan, perawatan monitoring tanaman bahkan menghitung prediksi hasil perkebunan penghasil gula, dalam hal ini adalah tanaman tebu (Saccharum officinarum L.). Perkebunan yang luas (skala besar) tentunya membutuhkan penanganan yang cukup besar dan biaya yang tidak sedikit. Berdasarkan data yang dimuat dalam situs Indonesian Commercial Newsletter (Datacon, 2007), salah satu industri perkebunan berskala besar adalah perkebunan tebu. Banyak perkebunan tebu di Indonesia yang memiliki luas lebih dari seribu hektar. Teknologi penginderaan jauh, melalui citra penginderaan jauh, memuat informasi spasial yang dapat digunakan untuk mengetahui kondisi suatu objek di lapangan secara tidak langsung. Dengan adanya informasi spasial yang akurat, maka dapat dilakukan kegiatan analisis dan pengembangan suatu objek yang berada di lapangan melalui citra penginderaan jauh, yang relatif murah, cepat dan dapat diketahui agihannya.

Permasalahan yang ada untuk pemanfaatan data penginderaan jauh adalah untuk melakukan analisis kondisi dilapangan secara tidak langsung melalui citra penginderaan jauh, maka dibutuhkan informasi spektral lapangan yang akurat sebagai acuhan supaya analisis yang dihasilkan sesuai dengan kondisi di lapangan. Dengan demikian diperlukan penelitian untuk mendapatkan informasi spektral tanaman tebu secara langsung dilapangan. Penelitian ini difokuskan pada identifikasi tanaman tebu dengan mengkorelasikan informasi spectral dari hasil pengukuran lapangan (in situ) menggunakan spektrofotometer dengan informasi band spectral dari citra penginderaan jauh.

Adapun tujuan dari penelitian ini adalah untuk melihat pola spectral tanaman tebu yang dihasilkan dari pengukuran melalui spektrofotometer di lapangan dan membandingkannya dengan pola spektral dari perekaman citra digital penginderaan jauh Landsat 8

Dengan dilakukan penelitian ini maka faedah yang diharapkan didapat dari penelitian ini adalah mendapatkan pola spectral yang didapatkan dari tanaman tebu sehingga pada kemanfaatan selanjutnya dapat digunakan untuk studi lebih mendalam mengenai pemetaan secara rinci terkait perkebunan tanaman tebu, termasuk didalamnya terkait biofisik tanaman sehingga dapat digunakan untuk mengatur manajemen yang lebih baik pada perkebunan tanaman tebu, yang akhirnya dapat digunakan untuk meningkatkan kesuksesan dalam tujuan berswasembada gula secara nasional.

\section{BAHAN DAN METODE PENELITIAN}

Bahan utama yang digunakan dalam penelitian ini adalah Citra Landsat 8 OLI path 120 row 65 perekaman 18 Mei 2017 yang merekam wilayah Bantul, pada saluran 1 hingga 5. Penggunaan saluran hanya difokuskan pada saluran 1 hingga 5 karena pengamatan yang dilakukan adalah pengamatan pola pantulan spektral objek tanaman tebu. Adapun peralatan yang digunakan dalam penelitian ini adalah :

a. Spectrometer Jaz Ocean Optics dengan seri JAZ-350 portable VIS-NIR, digunakan untuk pengukuran nilai pantulan spektral objek di lapangan.

b. GPS Handled, digunakan untuk melakukan plotting lokasi area tanaman tebu yang akan diukur nilai pantulan spektralnya.

c. Kamera, digunakan untuk melakukan dokumentasi pengamatan di lapangan.

Tahapan awal yang dilakukan dalam penelitian ini adalah melakukan koreksi radiometrik yang diperlukan guna memperbaiki kualitas citra terutama digunakan untuk tampilan secara visual guna mengetahui secara spasial agihan fenomena permukaan bumi yang terekam dalam citra landsat 8 . Tahapan selanjutnya adalah pemotongan citra dilakukan agar memudahkan proses interpretasi dan meringkas ukuran citra. dimana citra resolusi tinggi memiliki kapasitas data yang besar sehingga dapat mempercepat proses pengolahan data. Dengan melakukan pemotongan citra sesuai daerah penelitian maka citra yang ditampilkan hanya daerah liputan penelitian saja dan tidak membutuhkan waktu yang lama dalam proses pengolahan citra. 
Tahapan selanjutnya dalam penelitian ini dilakukan dengan terlebih dahulu menginterpretasi penutup lahan yang tampak pada citra untuk menentukan jenis penggunaan lahan. Proses interpretasi ini hanya menghasilkan informasi mengenai batas-batas penutup lahannya saja, sedangkan batas-batas khususnya perkebunan tebu belum bisa didapatkan sehingga dalam penelitian ini memerlukan informasi sekunder lokasi tanaman tebu yang didapatkan dari informasi petugas lapangan pabrik gula madukismo, selanjutnya informasi ini diselaraskan dengan citra landsat untuk digunakan pengambilan titik sampel yang akan digunakan padapengambilan data reflektan baik pada citra maupun pengukuran reflektan dilapangan menggunakan alat spectrometer. Survei lapangan yang dilakukan pada penelitian ini dilakukan untuk pengukuran spectral dilapangan menggunakan spektrofotometer. Penentuan sampel yang digunakan dalam survei ini menggunakan teknik purposived sampling. Teknik purposived sampling merupakan teknik pengambilan sampel dengan mengambil sampel dengan tujuan tertentu berdasarkan keberadaan tanaman tebu.

Hasil Pengukuran reflektan dilapangan dan dari citra landsat 8 selanjutnya dilakukan analisis pola spektral dan dilakukan perbandingan untuk mendapatkan karakteristik pola spektral tanaman tebu.

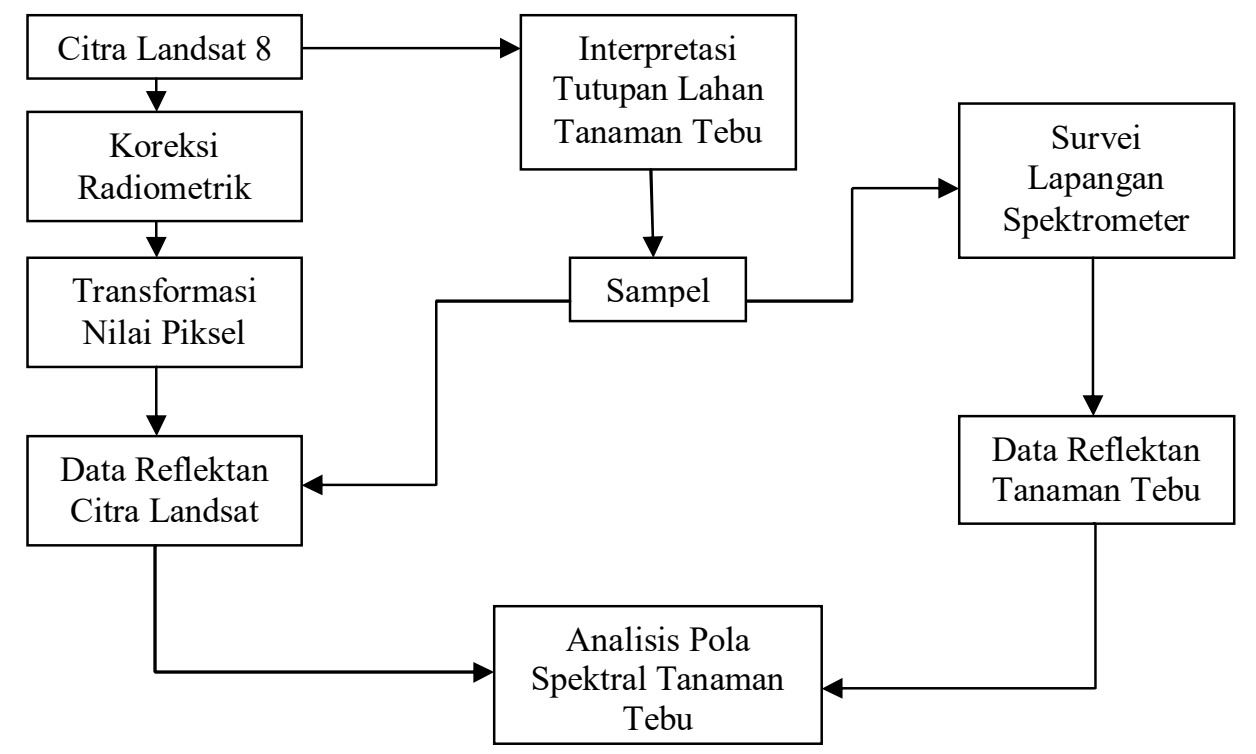

Gambar 1. Diagram Alir Penelitian

\section{HASIL DAN PEMBAHASAN}

Koreksi radiometrik dilakukan pada citra landsat untuk mengubah nilai DN pada citra menjadi nilai radian citra. Proses ini membutuhkan data Radiance Gains dan Radiance Offsets. Hasil dari kalibrasi radiometrik berupa tampilan citra yang lebih cerah. Tampilan citra pada kondisi sebelum dan sesudah koreksi dapat dilihat pada gambar 2 . 


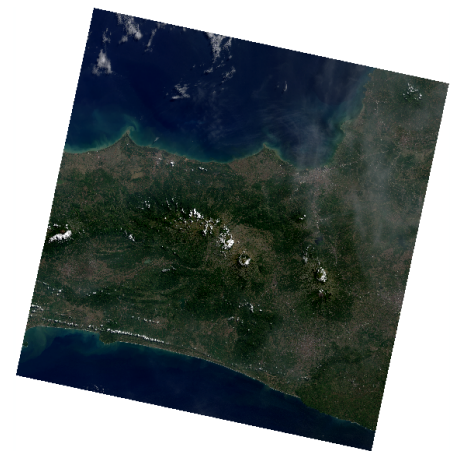

(a)

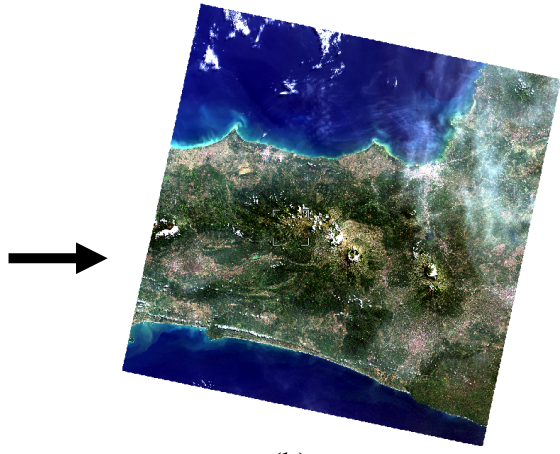

(b)

Gambar 2 Tampilan Citra Landsat 8 OLI pada komposit 432 sebelum koreksi radiometrik (a); sesudah koreksi (b)

Citra hasil koreksi radiometrik masih memiliki panjang gelombang dalam satuan mikrometer $(\mu \mathrm{m})$, sehingga perlu dilakukan perubahan format satuan panjang gelombang yang sesuai dengan format satuan panjang gelombang yang dimiliki spektrometer. Perubahan rentang nilai piksel minimum dan maksimum dapat dilihat pada tabel 1 .

Tabel 1 Perubahan Nilai Piksel pada setiap saluran citra Landsat 8

\begin{tabular}{|c|c|c|c|c|}
\hline Basic Stats & Min & Max & Mean & StdDev \\
\hline Band 1 & 0 & 45969 & 7064.188713 & 4631.011781 \\
\hline Band 2 & 0 & 48387 & 6411.910564 & 4232.233867 \\
\hline Band 3 & 0 & 49287 & 5736.720673 & 3831.989750 \\
\hline Band 4 & 0 & 52305 & 5122.095800 & 3497.570627 \\
\hline Band 5 & 0 & 61427 & 8677.081630 & 7177.867267 \\
\hline
\end{tabular}

Tabel 1.b.rentang nilai tiap saluran setelah koreksi radiometrik

\begin{tabular}{|c|c|c|c|c|c|}
\hline Basic Stats & Min & Max & Mean & StdDev \\
\hline Band 1 & 0.00 & 50.28 & 4.33 & 2.99 \\
\hline Band 2 & 0.00 & 54.52 & 3.61 & 2.61 \\
\hline Band 3 & 0.00 & 51.28 & 2.55 & 2.03 \\
\hline Band 4 & 0.00 & 46.19 & 1.55 & 1.52 \\
\hline Band 5 & 0.00 & 33.72 & 3.07 & 3.34 \\
\hline
\end{tabular}

Tabel 1.c. rentang nilai tiap saluran setelah koreksi atmosferik

\begin{tabular}{|c|c|c|c|c|}
\hline Basic Stats & Min & Max & Mean & StdDev \\
\hline Band 1 & 0.000000 & 1.000000 & 0.038990 & 0.041813 \\
\hline Band 2 & 0.000000 & 1.000000 & 0.030837 & 0.037272 \\
\hline Band 3 & 0.000000 & 1.000000 & 0.036108 & 0.040256 \\
\hline Band 4 & 0.000000 & 1.000000 & 0.028822 & 0.039565 \\
\hline Band 5 & 0.000000 & 1.000000 & 0.130112 & 0.146439 \\
\hline
\end{tabular}

Sumber : Pengolahan Citra

Perubahan kurva pantulan citra pada kondisi sebelum dan setelah proses koreksi dapat dilihat pada gambar 2.
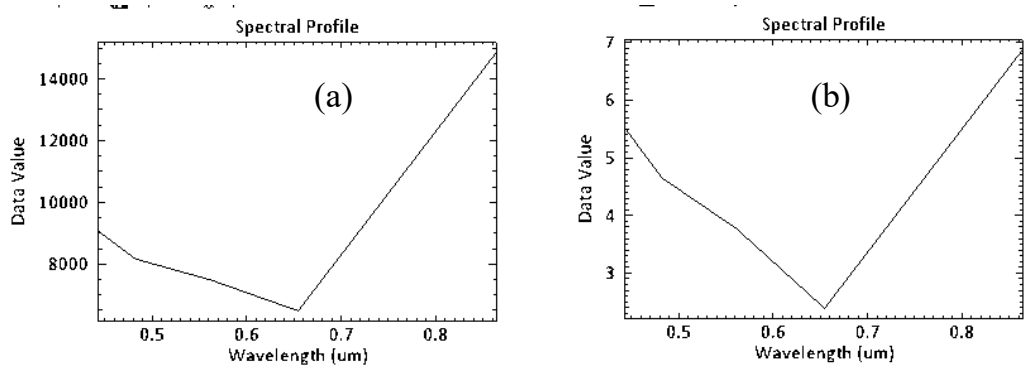


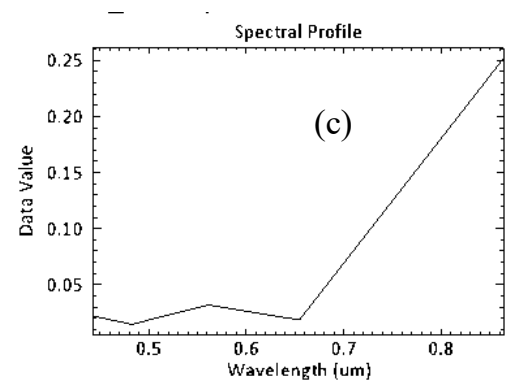

Gambar 3. Perubahan grafik data dan panjang gelombang citra untuk objek vegetasi pada

kondisi sebelum koreksi (a); setelah koreksi atmosferik (b); setelah koreksi atmosferik

Pengambilan sampel dilapangan dilakukan untuk mendapatkan spektral reflektan secara langsung dilapangan yang diukur menggunakan alat spectrometer. Terdapat 5 titik lokasi yang diambil untuk sebagai perwakilan tanaman tebu. Berikut adalah gambar lapangan pada salah satu titik di lapangan.

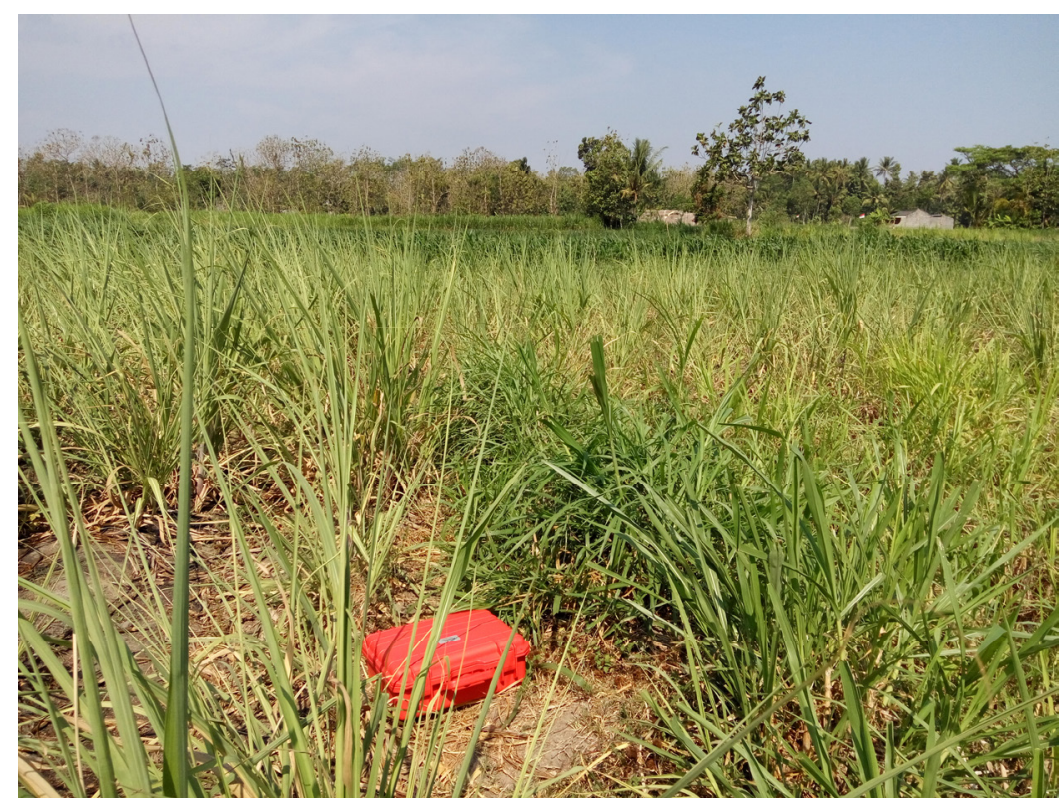

Gambar 4. Salah satu kondisi Tanaman Tebu di lapangan (7.887350 LS;110.304382 BT) yang digunakan sebagai salah satu titik sampel di lapangan

Keseluruhan sampel objek yang sudah direrata disajikan dalam satu file Microsoft Excel dengan format penyimpanan Text (Tab Delimited), untuk dapat dibandikan nilai pantulan antara kelima sampel objek tanaman tebu. Hasil dari perbandingan kelima sampel memberikan tingkat pola pantulan objek yang berbeda-beda tetapi memiliki bentuk kurva yang hampir sama dengan letak panjang gelombang yang sama pula. Kurva pantulan kelima sampel dapat dilihat pada gambar berikut 


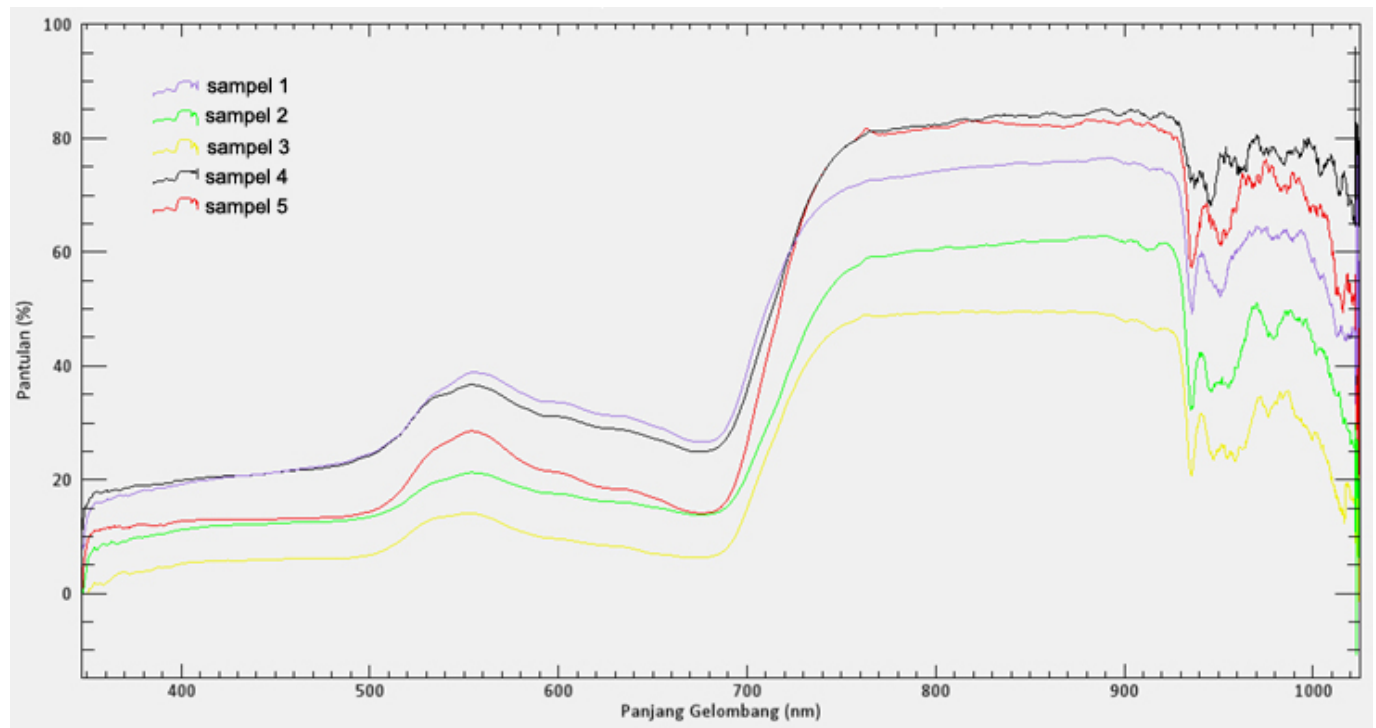

Gambar 5. Perbandingan kelima kurva pola pantulan sampel objek pada tanaman tebu

Perbedaan pola pantulan tersebut mengharuskan peneliti untuk mengambil keputusan data mana yang akan digunakan sebagai pola pantulan spektral tanaman tebu. Langkah yang diambil adalah dengan melakukan rerata lagi antara kelima sampel perekeman objek tanaman tebu tersebut. Adapun rerata dari ke lima kurva tersebut dihasilkan pola pantulan sebagai berikut.

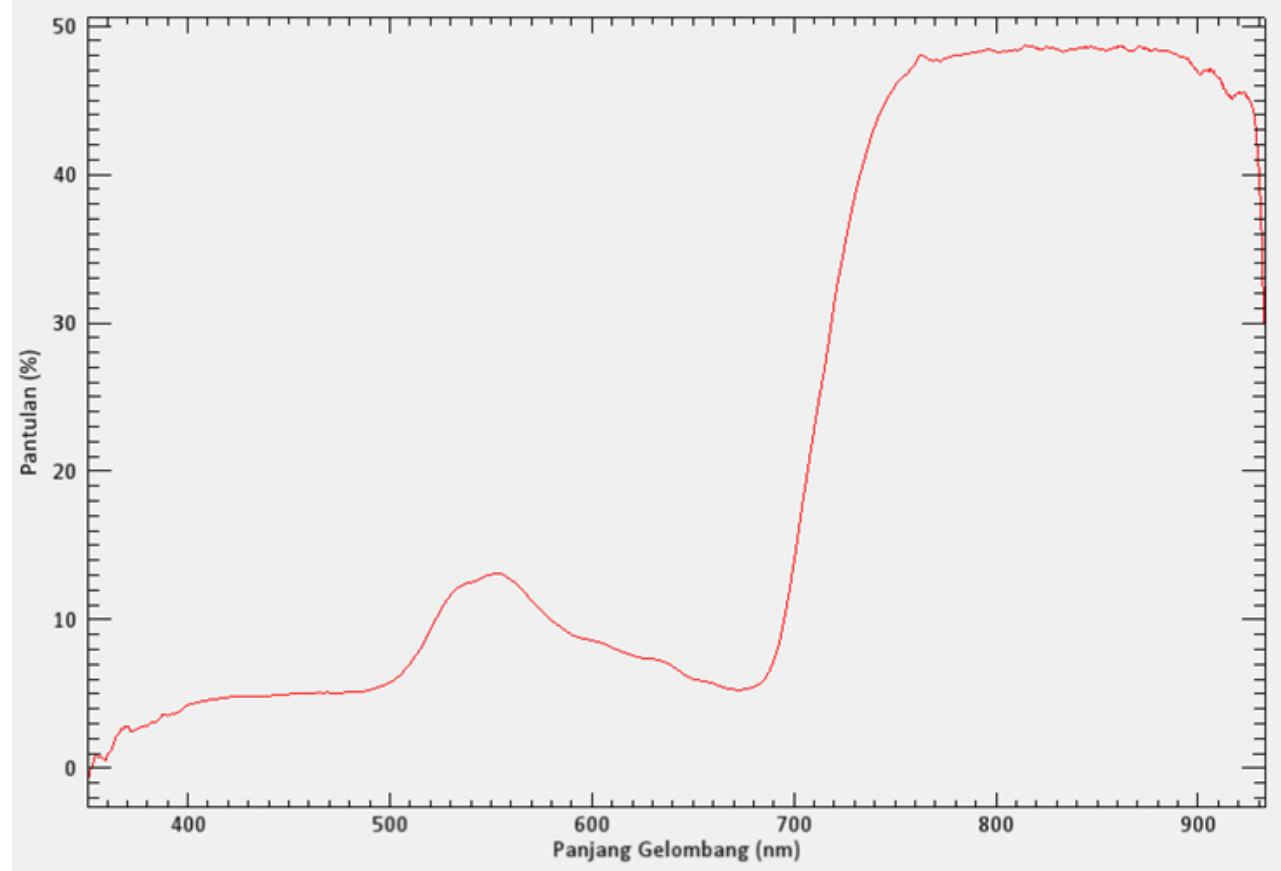

Gambar 6. Pola Pantulan Spektral Objek Tanaman tebu hasil rerata

Pola pantulan tanaman tebu dari pengukuran lapangan memiliki nilai dan kenampakan yang hampir sama dengan pola pantulan vegetasi pada umumnya, sehingga dapat diasumsikan bahwa hasil dari pengukuran pola pantulan cukup baik.

Pengambilan sampel pola pantulan spektral dari Citra Landsat 8 OLI dilakukan untuk digunakan sebagai bahan perbandingan pemetaan persebaran tanaman tebu berdasarkan pola pantulan spektral objek di lapangan. Pola pantulan spektral tanaman tebu dari citra ini juga digunakan sebagai 
pembanding uji akurasi pemetaan, apakah lebih baik menggunakan pantulan spektral objek dari citra atau menggunakan spektrometer.

Hasil yang diperoleh dari proses ini adalah spectral library tanaman tebu berdasarkan pengukuran pola pantulan spektral di lapangan dan spectral library tanaman tebu dari Citra Landsat 8 OLI. Perbedaan dapat dilihat pada penyajian kurva pantulan spectral library kedua data sebagai berikut :

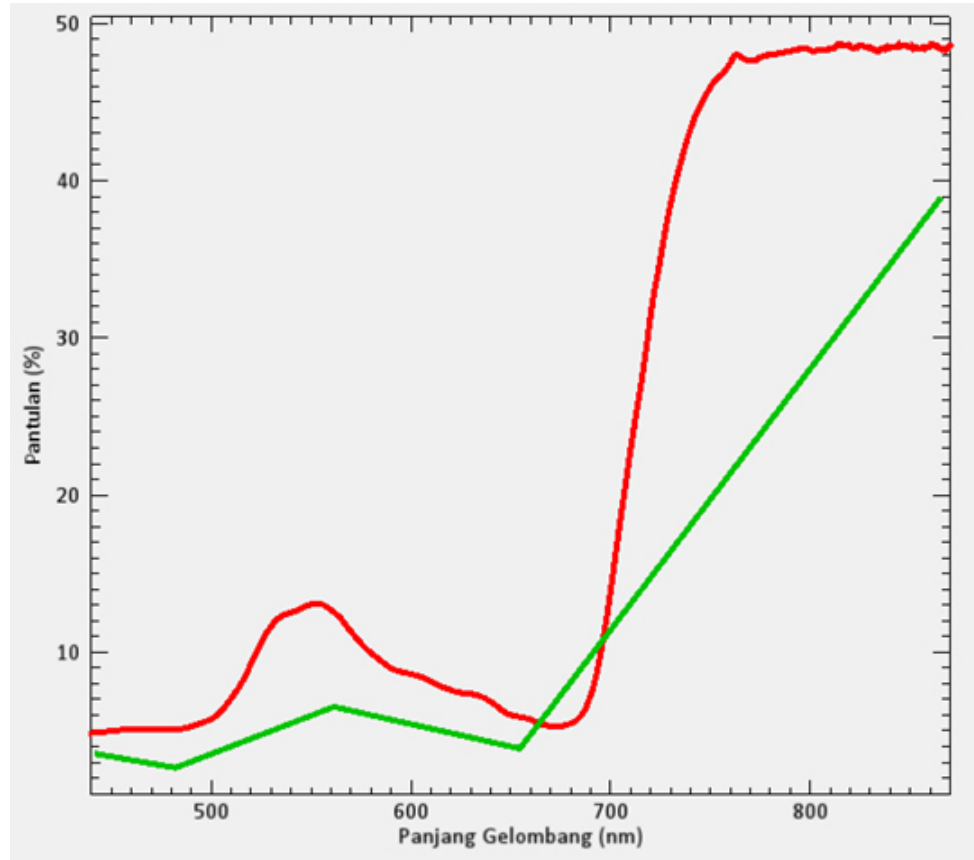

Gambar 7. Kurva spectral library dari pengukuran lapangan (warna merah) dan kurva spectral library dari Citra Landsat 8 OLI (warna hijau)

Kurva pantulan dari lapangan memiliki rentang panjang gelombang dari sekitar 350-950 nm, sedangkan kurva pantulan dari citra hanya memiliki rentang panjang gelombang mulai dari 430-880 $\mathrm{nm}$. Hal tersebut dipengaruhi oleh kemampuan dan speksifikasi spektrometer dan citra yang berbeda dalam menangkap informasi spektral objek dipermukaan bumi, khususnya tanaman tebu. Spektrometer pada setiap salurannya mampu membaca pola spektral dalam 0,4 nm, sedangkan Citra Landsat 8 OLI setiap salurannya rata-rata hanya mampu membaca pola spektral dalam rentang 30 hingga $60 \mathrm{~nm}$. Selain itu, saluran Citra Landsat 8 OLI yang digunakan dalam penelitian hanya berjumlah 5 saluran, dimulai dari Aerosol hingga NIR secara berurutan.

\section{KESIMPULAN}

Kesimpulan penelitian ini memberikan gambaran tentang karakteristik pola spektral atau pola reflektansi pada tanaman tebu sehingga dapat digunakan untuk pemetaan agihan tanaman tebu di wilayah Kabupaten Bantul. Kurva pantulan Tanaman Tebu dari pengukuran lapangan terlihat lebih halus dan memiliki jumlah panjang gelombang lebih banyak dibandingkan dengan kurva pantulan dari Citra Landsat 8 OLI. Spectral library pengukuran lapangan dan Citra Landsat 8 OLI menunjukkan bahwa spectral library pengukuran lapangan lebih baik untuk dijadikan sebagai dasar pemetaan berbasis spektral dibandingkan dengan spectral library hasil pengambilan sampel pada Citra Landsat 8 OLI

\section{SARAN}

Perlu dilakukan penelitian lanjutan untuk diaplikasikan kedalam proses pemetaan dan dilakukan uji akurasi hasil yang didapatkan. 


\section{DAFTAR PUSTAKA}

Anderson, James R., Ernest E. Hardy, John T. Roach, Richard E. Witmer. 1976. A Land Use And Land Cover Classification System For Use With Remote Sensor Data. Geological Survey. USA

Anonim. 2011. Ketahanan Pangan. https://id.wikipedia.org/wiki/Ketahanan_pangan.Diakses pada 08 Maret 2016

Anonim. 2012. Gula. https://id.wikipedia.org/wiki/Gula. Diakses pada 08 Maret 2016

Kementerian Koordinator Bidang Perekonomian. 2014. Kebijakan Gula Untuk Ketahanan Pangan Nasional. Diakses pada 08 Maret 2016

Badan Litbang, 2005. Prospek dan Arah pengembangan Agribisnis Tebu. Departemen Pertanian. Jakarta.

Campbell, James B., 2002. Introduction to Remote Sensing. Third edition. The Guilford Press, New York-London.

Curtiss, B and Goetz, AFH 1994, Field spectrometry: techniques and instrumentation, In Proceedings of the International Symposium on Spectral Sensing Research, San Diego, July 10-15, pp. 195-203.

Danoedoro, 1996. Pengolahan Citra Digital. Fakultas Geografi UGM. Yogyakarta

Gao, Jay, 2009. Digital Analysis of Remotely Sensed Imagery. The McGraw-Hill Comapnies. AS

Goetz, AFH, Vane, G, Solomon, JE \& Rock, BN 1985, 'Imaging Spectrometry for Earth RemoteSensing', SCIENCE, vol. 228, pp.1147-1153.

Janssen, Lucas L. F. dan Gerrit C. Huurneman (Ed.), 2001. Principles of Remote Sensing. ITC. Netherland

Lillesand, Thomas M., Ralph W. Kiefer, Jonathan W. Chipman, 2004. Remote Sensing and Image Interpretation. Fifth Edition. John Willey and Son. New York, USA

Milton, EJ 1987, 'Principles of field spectroscopy', International Journal of Remote Sensing, vol. 8, pp. 1807-1827.

Milton, EJ, Schaepman, ME, Anderson, K, Kneubühler, M \& Fox, N 2009, 'Progress in field spectroscopy', Remote Sensing of Environment, vol. 113, pp. S92-S109.

Mona Tobing. 2013. http://industri.kontan.co.id/news/ini-lima-arah-kebijakan-swasembada-gulakementan. Diakses pada 08 Maret 2016

Sutanto. 2013. Metode Penelitian Penginderaan Jauh. Yogyakarta: Penerbit Ombak.

Wessman, CA 1992, 'Imaging spectrometry for remote sensing of ecosystem processes', Advances in Space Research, vol. 12, pp. 361-368. 